\title{
Use of Evapotranspiration (ET) Landfill Covers to Reduce Methane Emissions from Municipal Solid Waste Landfills
}

\author{
Tarek Abichou ${ }^{*}$, Tarek Kormi ${ }^{2}$, Cheng Wang ${ }^{3}$, Haykel Melaouhia ${ }^{1}$, Terry Johnson ${ }^{4}$, \\ Stephen Dwyer ${ }^{5}$ \\ ${ }^{1}$ Department of Civil Engineering, Florida State University, Tallahassee, FL, USA \\ ${ }^{2}$ Ecole Nationale d' Ingenieurs de Gabes, Department de Genie Civil, Gabes, Tunisia, LASMAP, Ecole \\ Polytechnique de Tunisie, University of Carthage, Tunisia \\ ${ }^{3}$ Argonne National Laboratory, Chicago, IL, USA. \\ ${ }^{4}$ Waste Management, Minneapolis, MN, USA. \\ ${ }^{5}$ Dwyer Engineering, Albuquerque, NM, USA \\ Email: ${ }^{*}$ abichou@eng.fsu.edu
}

Received 24 August 2015; accepted 15 September 2015; published 21 September 2015

Copyright (C) 2015 by authors and Scientific Research Publishing Inc.

This work is licensed under the Creative Commons Attribution International License (CC BY). http://creativecommons.org/licenses/by/4.0/

(c) (i) Open Access

\section{Abstract}

Solid waste landfills need to have final covers to 1 ) reduce the infiltration of rainfall into the waste mass and 2) reduce surface greenhouse gas emissions. Most regulations require that such final covers include hydraulic barriers, such as compacted clays with or without geomembrane. Significant research has been undertaken to allow the use of evapotranspiration-based covers (often termed: Evapotranspiration (ET) Cover, Water Balance Covers, or Phyto Covers) as an alternative to the barrier concept covers. ET covers are designed so that they have the capacity to store water by the soil and also have plants or vegetation to remove the stored water. In ET covers, plant roots can enhance the aeration of soil by creating secondary macropores which improve the diffusion of oxygen into soil. Therefore, biological methane oxidation (a natural process in landfill soils) can be improved considerably by the soil structuring processes of vegetation, along with the increase of organic biomass in the soil associated with plant roots. This paper summarizes a study to investigate the capacity of an ET cover to reduce surface greenhouse gas emissions when implemented on a solid waste landfill. This study consisted of using a numerical model to estimate methane emission and oxidation through an ET cover under average climatic conditions in Bennignton, Nebraska, USA. Different simulations were performed using different methane loading flux (5 to $200 \mathrm{gm}^{-2} \cdot \mathrm{d}^{-1}$ ) as the bottom boundary. For all simulations, surface emissions were the lowest

*Corresponding author.

How to cite this paper: Abichou, T., Kormi, T., Wang, C., Melaouhia, H., Johnson, T. and Dwyer, S. (2015) Use of Evapotranspiration (ET) Landfill Covers to Reduce Methane Emissions from Municipal Solid Waste Landfills. Journal of Water Resource and Protection, 7, 1087-1097. http://dx.doi.org/10.4236/jwarp.2015.713089 
during the growing season and during warmer days of the year. Percent oxidation is the highest during the growing season and during warmer days. The lowest modeled surface emissions were always obtained during the growing season. Finally, correlations between percent oxidation and methane loading into simulated ET covers were proposed to estimate methane emissions and methane oxidation in ET covers.

\section{Keywords}

\section{Evapotranspiration Covers, Methane Oxidation, Landfills, Greenhouse Gas Emissions}

\section{Introduction}

\subsection{Background}

Final covers are used to reduce the quantity of water that infiltrates into waste deposits at landfills. Reducing the volume of infiltrating water reduces the amount of leachate that is generated and the risk of groundwater contamination. Generally, the applicable rules and regulations require that landfill covers employ resistive principles, i.e., layers having low saturated hydraulic conductivity such as compacted clay barriers, geosynthetic clay liners with or without a geomembrane. This design philosophy is often referred to as "raincoat", barrier, or "umbrella" approach. Barrier type covers, such as compacted clay covers, have been shown to loose their impermeable qualities over time because of the influence of climate variations on the integrity of the soil layer [1]. The United States Environmental Protection Agency (USEPA) final cover regulations require a provision for the use of alternative final covers as long as they provide: 1 ) an infiltration layer that provides equivalent reduction in infiltration to that of the prescribed cover and 2) an erosion layer that provides equivalent protection from wind and water erosion as the one of the prescribed cover. One type of an alternative is to design landfill covers to exploit the water storage capacity of finer textured soils and the water removal capability of vegetation [2]-[6]. This type of cover is referred to as an evapotranspiration or ET cover.

Evapotranspiration (ET) covers are earthen final covers that control the percolation of infiltrating rainwater into the waste by balancing the water storage capacity of finer textured soils and the ability of plants to extract the water stored. They are designed to transmit equal or less percolation than the conventional resistive covers built with low hydraulic conductivity materials. Evapotranspiration (ET) covers (also referred to as: water balance covers, "store and release" covers, phyto-covers) are designed to have a capacity to store water by the soil and also to have the capacity to remove the stored water. Therefore, ET covers are essentially well-designed-vegetated soil landfill covers. The soil layer (s) of an ET cover stores moisture during rain events, and the sun and plants remove the water from the soil by evaporation and evapotranspiration, returning the moisture to the atmosphere.

Under landfill setting, final covers are also exposed to landfill gases from the waste mass below. Landfill gas is composed of $50 \%$ by volume of methane. Landfill gas is transported by diffusive and convective flux mechanisms from the anaerobic zone toward the atmosphere. The microbiological process of oxidizing $\mathrm{CH}_{4}$ to $\mathrm{CO}_{2}$ by methanotrophs is called microbial $\mathrm{CH}_{4}$ oxidation. Several previous studies on landfill $\mathrm{CH}_{4}$ oxidation in soil cover layers have demonstrated the ability of methane oxidation as a mechanism to reduce $\mathrm{CH}_{4}$ emissions from landfill surfaces [7]-[13]. However, the capacity of landfill cover soil to oxidize $\mathrm{CH}_{4}$ depends on both the physical and the chemical properties of landfill cover materials such as soil type, moisture content, density, organic and nutrient content, etc. Additionally, environmental conditions such as temperature and precipitation can also impact the performance of landfill cover soils in terms of oxidizing $\mathrm{CH}_{4}$.

In ET cover context, methane oxidation is impacted by vegetation, water content and soil temperature. The soil water content and the soil temperature in the soil profile govern gas transport and therefore methane oxidation in ET covers. Water content in the ET cover soil profile is a very important factor affecting $\mathrm{CH}_{4}$ oxidation in landfill cover soils. First, the optimum environment for $\mathrm{CH}_{4}$-oxidizing bacteria (methanotrophic) is obtained within a specific water content range. Second, water content affects the penetration of $\mathrm{O}_{2}$ into cover soils and $\mathrm{O}_{2}$ is the main reactor for $\mathrm{CH}_{4}$ oxidation. As water content increases in soil, $\mathrm{O}_{2}$ diffusion into the soil is hindered. 
Third, water content affects the air-filled porosity of soil thus influences gas transport. As water fills up voided pores within the cover soil, it blocks the flow of gas upward. [14] and others correlated microbial activity with water content. Soil temperature also affects the bacterial activity of methane oxidizing bacteria. [14] and others correlated soil temperature to bacterial methane oxidation. In ET cover setting, these water content and soil temperature are dynamic and vary with time and with depth as a function of climatic conditions, vegetation, and soil hydraulic properties. In order to accurately predict methane oxidation in ET covers, landfill covers, the changing water content and temperature inside a cover has to be accounted for. In order to better predict gas emissions and methane oxidation in landfill covers, the changing water content and temperature inside the soil profile has to be accounted for in any numerical solution.

\subsection{Motivations and Objectives}

The potential superior capability of ET covers to reduce fugitive release of methane to the atmosphere is an additional characteristic that should be considered to encourage the use of the types of covers. The basis of ET cover design is the predictive capabilities of the water balance modeling and the ability to quantify the maximum water infiltration from the atmosphere into the waste mass below the ET cover. ET covers provide a unique opportunity to introduce a modeling approach to methane oxidation in landfill covers since the modeling approach is already undertaken during the water balance assessment of the design. The objective of this study is to use a similar modeling methodology for methane oxidation to extend the water balance modeling-based design associated with ET covers to estimate gas transport and methane oxidation in and across an ET cover. The modeling approach consists of modeling gas transport using our existing gas transport and oxidation model. Our model accounts for dynamic parameters associated with the change in water content and temperature caused by change in climatic conditions at the upper boundary of the ET cover. The model also incorporates the changing temperature and water content to methanotrophic activity in the soil. The numerical model (FSU Model) is developed by our research team at Florida State University and combines water and heat flow with a gas transport and oxidation [14]-[18]. The modeling methodology is applied to an actual ET cover test section being assessed for hydraulic equivalency in Bennington Nebraska, USA.

\section{Methods}

\subsection{Site Description}

An ET cover was constructed and monitored as a demonstration project in Bennington, Nebraska. Bennington, $\mathrm{NE}$, receives $760 \mathrm{~mm}$ of rain per year. Snowfall is $740 \mathrm{~mm}$. The number of days with any measurable precipitation is 92. On average, there are 216 sunny days per year in Bennington, NE. The July high temperature is around $30^{\circ} \mathrm{C}$. The January low is $-11^{\circ} \mathrm{C}$. The project was intended to demonstrate that an ET cover as constructed in the demonstration project is functionally equivalent to the regulatory default cover based on water balance performance. The cover demonstration profile was constructed and instrumented in 2008. The instrumentation was activated during December 2008. The demonstration cover surface was then seeded in 2009. Surface vegetation and underlying rooting have been established. The soil moisture measurement equipment utilized on this project includes water content sensors and water potential sensors (soil suction). There were two sets of probes installed in instrumentation nests. Figure 1 shows the placement and depth spacing for the probes installed in each nest. Instrumentation nests were installed in two locations (Nest A and B). Each nest consists of 7 water content sensors and 7 water potential sensors. A water content and water potential sensor is installed at each depth indicated in Figure 1. Nest A was installed in the demonstration cover profile with a gentle slope (3.33\%) that attempts to mimic the top surface of the landfill and is within that recommended by RCRA of 2 to $5 \%$. Nest B was placed in the profile on a steeper slope ( $25 \%$ or $4: 1)$ in an attempt to mimic steeper side slopes of the landfill. All of the nests of probes were connected to a central data logger. The weather station is co-located with the data logger. The equipment at this central location was mounted on a tripod in a weather resistant enclosure and lighting protection. The water balance aspect of the collected data is not addressed in this paper. Only the soil water content and potential data collected at each depth of Nest A and Nest B were averaged and used to estimate the Van Genunchten parameters describing the unstaured hydraulic properties of the ET cover layers as described later. 

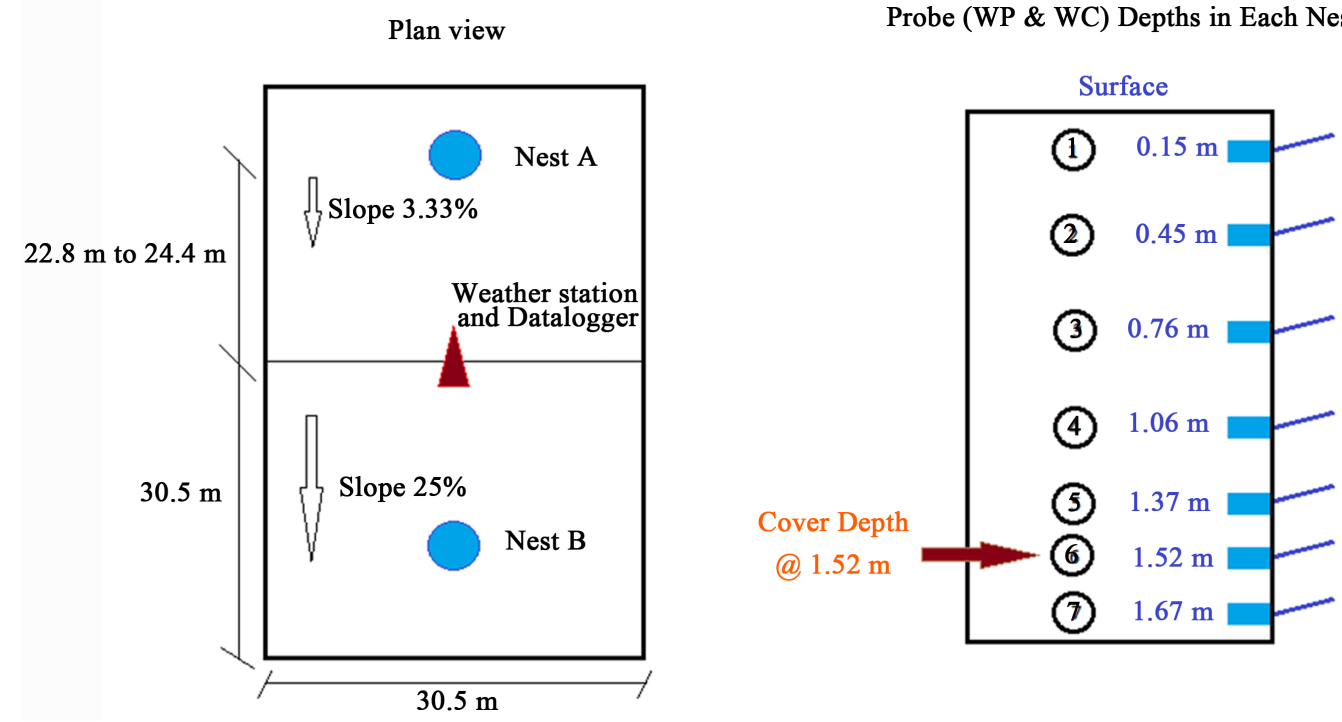

Figure 1. Plan view and profile of instrumentation nests installed in ET cover.

\subsection{Model Description}

A numerical model (FSU Model) was developed by our research team at Florida State University that combined water and heat flow with a gas transport and oxidation model [14]-[18]. The latest version of the FSU model was bundled via a graphical user interface and was renamed the Landfill Surface Emission Model (Land SEM).

The new Land SEM model comprises four major modules, bundled via a graphical user interface:

- A climate module which generates daily minimum and maximum air temperature along with daily rainfall based on the landfill site geographical location.

- A soil property generation module which generates soil properties, e.g. saturated hydraulic conductivity, porosity, and methane oxidation capacity based on a built-in database of soil property data from the literature. The user can also input measured soil properties, if available.

- A soil water content and temperature simulation module which uses the landfill site location, soil texture information and the climate generation data developed in the first two steps and then predicts the daily soil moisture and temperature at any depth of the soil cover profile for an average climatic year.

- A core computational module, based on [14]-[18], which simulates the concentration and flux of the gas components including methane in the landfill cover soil profile.

The climate simulator is a module adopted from the models Global Temp SIM and Global Rain [19], including an air temperature simulation and precipitation simulation. The air temperature generation predicts the daily average air temperature based on a 30-year (1961-1990) temperature records and calculate the daily maximum and minimum air temperature. The global rainfall module estimates daily rainfall patterns for a yearly cycle based on a 30-year (1961-1990) global average monthly precipitation records. The information obtained from these modules together with the soil properties are used in the soil water content and temperature simulators. Global Temp SIM and Global Rain were used to estimate daily average air temperatures and average daily precipitation for Bennington, Nebraskausing the climate generation module with the USA postal service Zip Code as the main input.

The continuity equation describing the reactive transport of gas component $i$ in landfill cover soils can be written [14]

$$
\varepsilon \frac{\partial C_{i}}{\partial t}=-\nabla \cdot J_{i}+\rho_{\text {bulk }} \cdot r_{i}
$$

where $\varepsilon$ is air-filled porosity $\left(\mathrm{m}_{\text {gas }}^{3} / \mathrm{m}_{\text {soil }}^{3}\right), C_{i}$ is the molar concentration of gas component $i\left(\mathrm{~mole} \cdot \mathrm{m}^{-3}\right)$, $J_{i}$ is the flux of gas component $i$ due to advection and diffusion $\left(\mathrm{mol} \cdot \mathrm{m}^{-2} \cdot \mathrm{s}^{-1}\right), \rho_{\text {bulk }}$ is the bulk density of 
soil $\left(\mathrm{kg} \cdot \mathrm{m}^{-3}\right)$, and $r_{i}$ is the production rate of gas component $I\left(\mathrm{~mol} \cdot \mathrm{kg}_{\text {drys }}^{-1} \cdot \mathrm{s}^{-1}\right)$. In Equation (1), the first time on right hand side represents the transport process while the second term accounts for the soil gas reaction (oxidation for methane).

The flux $J_{i}$ can be determined by

$$
J_{i}=-D_{\text {soil }, i} \nabla C_{i}+v C_{i}
$$

where $D_{\text {soil, } i}$ is the diffusion coefficient of component $i$ in soil $\left(\mathrm{m}^{2} \cdot \mathrm{s}^{-1}\right), \quad v$ is the flow velocity of gas mixture in the soil $(\mathrm{m} / \mathrm{s})$.

The diffusion coefficient $D_{\text {soil, }}$ can be calculated from its relationship with the diffusion coefficient in gas mixture,

$$
D_{\text {soil }, i}=\gamma D_{\text {gas }, i}
$$

where $\gamma$ is the relative diffusion coefficient of gas in a tortuous void space in soil and $D_{\text {gas, } i}$ is the diffusion coefficient of gas component $i$ in gas mixture. The relative diffusion coefficient $\gamma$ has been found to be independent to the gas itself [20] [21]. Although several formulation of $\gamma$ based on air content in soils have been proposed (e.g. [22] [23]), the following equations by [24] is used in this research,

$$
\gamma=\frac{\varepsilon^{2.5}}{\phi}
$$

where $\phi$ is total porosity $\left(\mathrm{m}_{\text {void }}^{3} / \mathrm{m}_{\text {soil }}^{3}\right)$.

The gas flow velocity is due to advection and is assumed to follow Darcy's law.

$$
v=-\frac{k}{\mu} \frac{\partial P}{\partial x}
$$

where $k$ is the intrinsic permeability of soil $\left(\mathrm{m}^{2}\right), \mu$ is the gas-mixture viscosity, $P$ is pressure (Pa) which is calculated based on the ideal gas law

$$
P=\sum_{i=1}^{n} C_{i} \cdot R \cdot T
$$

where $R$ is the universal gas constant $\left(8.314 \mathrm{~J} \cdot \mathrm{K}^{-1} \cdot \mathrm{mol}^{-1}\right)$ and $T$ is absolute temperature (K).

The reaction rate of $\mathrm{CH}_{4}$ is given

$$
r_{\mathrm{CH}_{4}}=V_{\max } \frac{C_{\mathrm{CH}_{4}}}{K_{m\left[\mathrm{CH}_{4}\right]}+C_{\mathrm{CH}_{4}}} \frac{C_{\mathrm{O}_{2}}}{K_{m\left[\mathrm{O}_{2}\right]}+C_{\mathrm{O}_{2}}}
$$

where $V_{\max }$ is the maximum methane consumption rate $\left(\mathrm{nmol} \cdot \mathrm{s}^{-1} \cdot g_{\mathrm{dry} s o i l}^{-1}\right)$; and $K_{m\left[\mathrm{CH}_{4}\right]}$ and $K_{m\left[\mathrm{O}_{2}\right]}$ are the half-saturation constants of $\mathrm{CH}_{4}$ and $\mathrm{O}_{2}\left(\mathrm{~mol} \cdot \mathrm{m}^{-3}\right)$, respectively. Methane oxidation is affected by many factors among which soil temperature and moisture content are more significant. Temperature, moisture, and scaling correction factors were considered for the kinetic parameters in Equation (7) as described in [18]. [14] developed a mechanism to relate in situ rates of oxidation to those measured in laboratory incubation experiments on homogenized and sieved soil samples under fixed environmental conditions. Their study used combined laboratory and field measurements to develop field scale Michaelis-Menten parameters to be used in conjunction with numerical models to predict methane emissions and oxidation in landfill covers and under field conditions. More details about the model can be found in [14]-[18]. Since the surface of the phytocap is open to the atmosphere, the gas composition above the surface node of the model was assumed to be the atmospheric gas compositions (background), which are 21.2\%v/v oxygen, 1.8 ppmv methane, $385.0 \mathrm{ppmv}$ carbon dioxide and 78.8\%v/v nitrogen.

\subsection{Simulations}

The simulated ET cover was divided into five30-cm-thick layers with different soil properties. The top layer was 
assumed to be $30 \mathrm{~cm}$ thick and represented by the $15 \mathrm{~cm}$ deep soil water and soil suction sensors. The second layer was also assumed to be $30 \mathrm{~cm}$ thick and be represented by the sensors buried at $45 \mathrm{~cm}$, etc. The top $60 \mathrm{~cm}$ ET cover soil was assumed to have undergone several freeze-thaw and desiccation cycles. The long-term saturated hydraulic conductivity of the top 30 -cm-thick layer was assigned to be $1 \times 10^{-4} \mathrm{~cm} / \mathrm{s}$. The second layer was a signed to have a saturated hydraulic conductivity of $1 \times 10^{-5} \mathrm{~cm} / \mathrm{s}$. The third layer was assumed to have a 10 times lower saturated hydraulic conductivity. The hydraulic conductivity of the lowest layer was measured from an undisturbed sample as $2.7 \times 10^{-7} \mathrm{~cm} / \mathrm{s}$. The hydraulic conductivity of the second layer from the bottom was assumed to be 5 times higher than the bottom layer. The porosity of the soil profile was assumed as follow: from top to down $0.45,0.42,0.40,0.38$, and 0.38 . The long term unsaturated soil properties are shown in Figure 2. The collected daily moisture content (moisture content sensor) and soil suction (matric potential sensor) value for a given elevation (each probe depth) were used to directly measure a field determined soil water characteristic curve (Figure 2). The in situ determination of a SWCC for the soil is more representative of the actual conditions than the SWCC developed in the laboratory. Figure 2 shows the soil properties used as input into the model for all the simulated layers of the ET cover and three examples of field determined SWCCs.

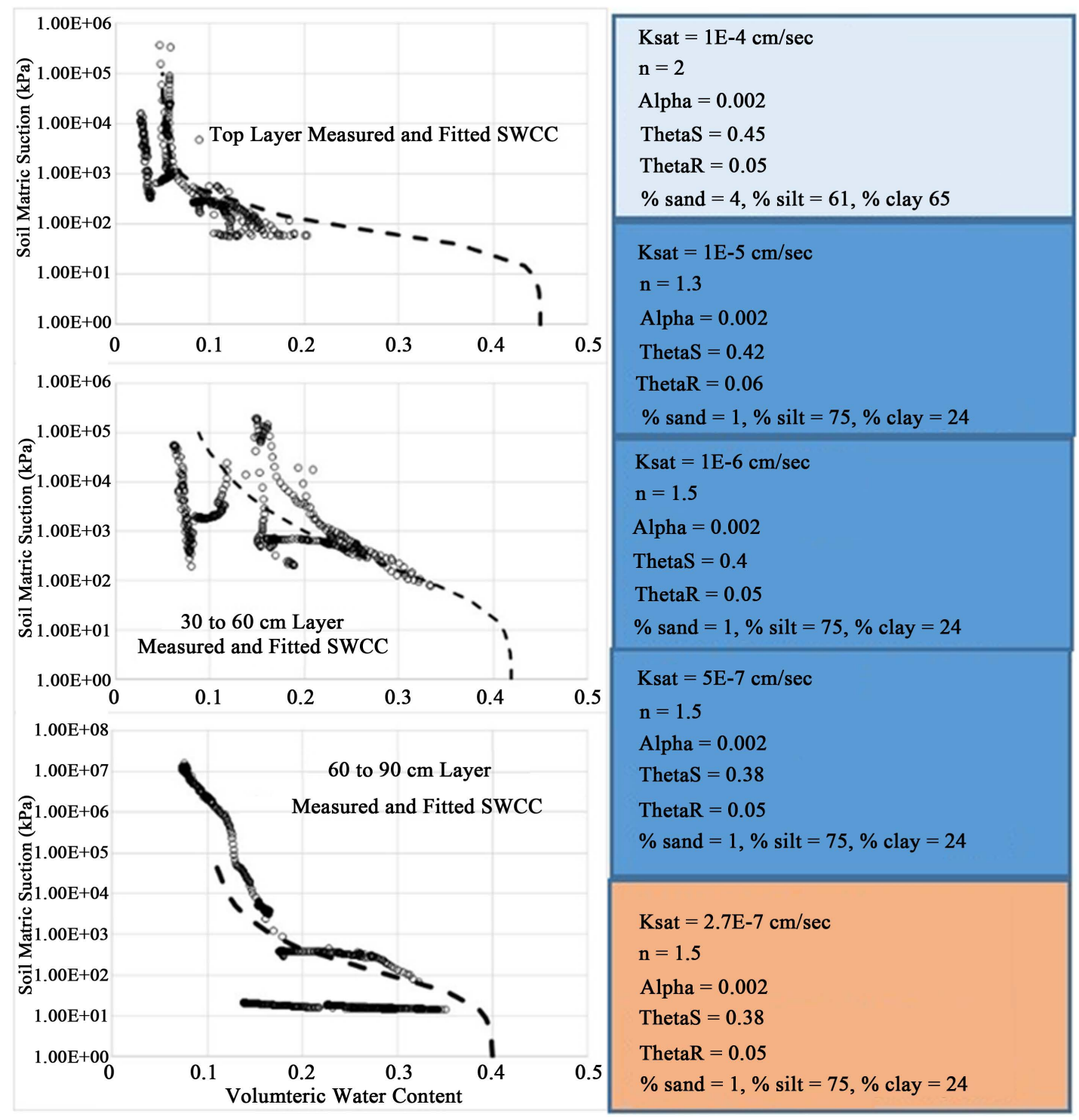

Figure 2. Examples of measured and fitted SWCC obtained using collected data, along with all soil properties used for each layer of the simulated ET cover. 
One of the major inputs to the gas transport model is the maximum methane oxidation capacity (a lab measured quantity $V_{\max }$ ) of the soil. This quantity represents the maximum capacity of bacteria in the soil to oxidize methane at room temperature. Based on our experience with measuring $V_{\max }$ on landfill cover soils and for the purpose of this document, different simulations of two different values of $V_{\max }\left(150,300 \mathrm{nmol} \cdot \mathrm{s}^{-1} \cdot \mathrm{g}^{-1}\right.$ dry soil $)$ were performed. Several simulations were performed using different rates of methane loading into the ET cover. For each $V_{\max }$, several simulations were performed using methane loading varying from 2 to $200 \mathrm{gm}^{-2} \cdot \mathrm{d}^{-1}$. The landfill gas entering the bottom of soil profile was partitioned equally to $\mathrm{CH}_{4}$ and $\mathrm{CO}_{2} \mathrm{v} / \mathrm{v}$.

\section{Results and Analysis}

The output of the gas transport model consists of daily surface emissions of methane and daily percent oxidized for each simulation performed with each methane loading flux (MLF) during the modelled average one year period in Bennignton, NE. The daily simulations was repeated for different MLFs (2, 5, 10, 20, 50, 100, 200 $\mathrm{gm}^{-2} \cdot \mathrm{d}^{-1}$ ) and with each $V_{\max }$. Figure 3 and Figure 4 show the daily surface emissions and daily percent methane oxidation for all the simulations with different MLFs and with $V_{\max }$ of $150 \mathrm{and} 300 \mathrm{nmol} \cdot \mathrm{s}^{-1} \cdot \mathrm{g}^{-1}$ dry soil, respectively.

Figure 3 and Figure 4 show that for MLF values of 2 to $5 \mathrm{gm}^{-2} \cdot \mathrm{d}^{-1}$, noneto very little surface emissions occur during the entire year. The ET cover seems to be able to oxidize all of the incoming methane from below each day of the year, even during cold seasons and inside and outside the growing season. Complete oxidation (100\%) occurs every day of the year when the MLF is lower than around $5 \mathrm{gm}^{-2} \cdot \mathrm{d}^{-1}$. For simulations with a higher MLF values, the highest daily surface emissions and lower percent oxidation occur outside the growing season and
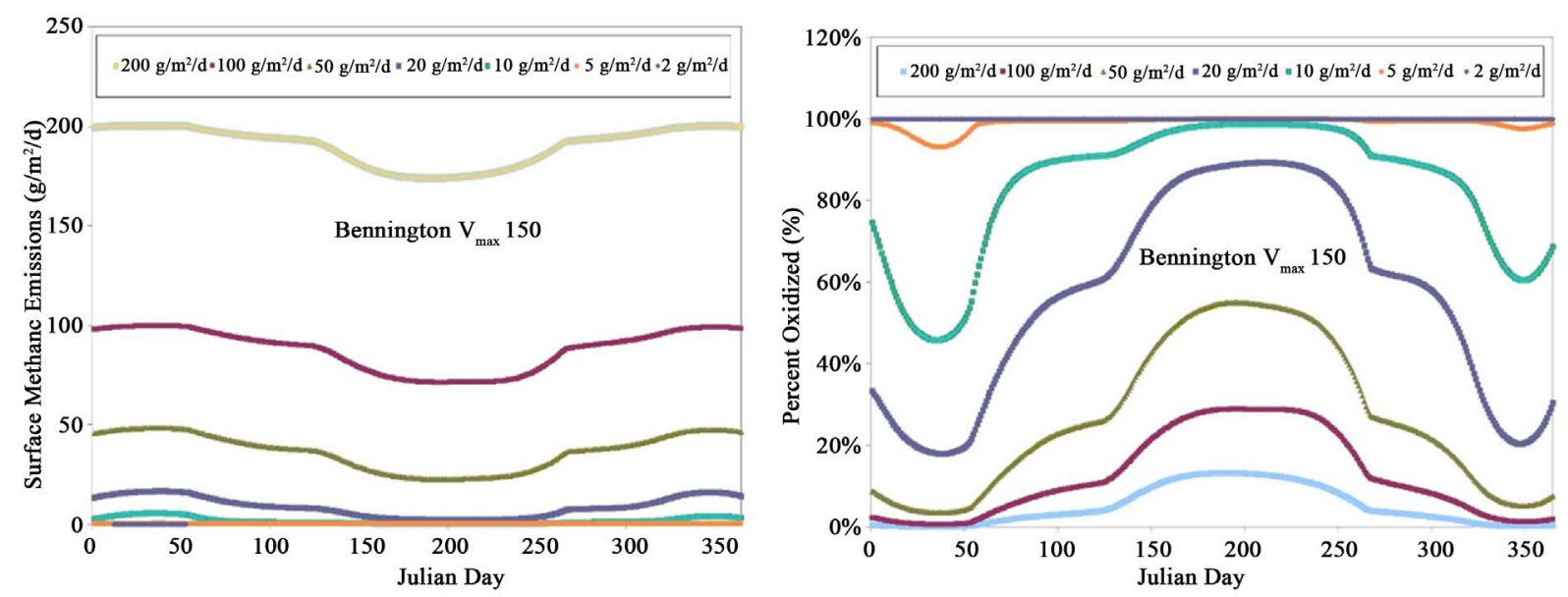

Figure 3. Surface emissions, percent oxidized for several methane loading fluxes with $V_{\max }=150 \mathrm{nmol} \cdot \mathrm{s}^{-1} \cdot \mathrm{g}^{-1} \mathrm{dry}$ soil.
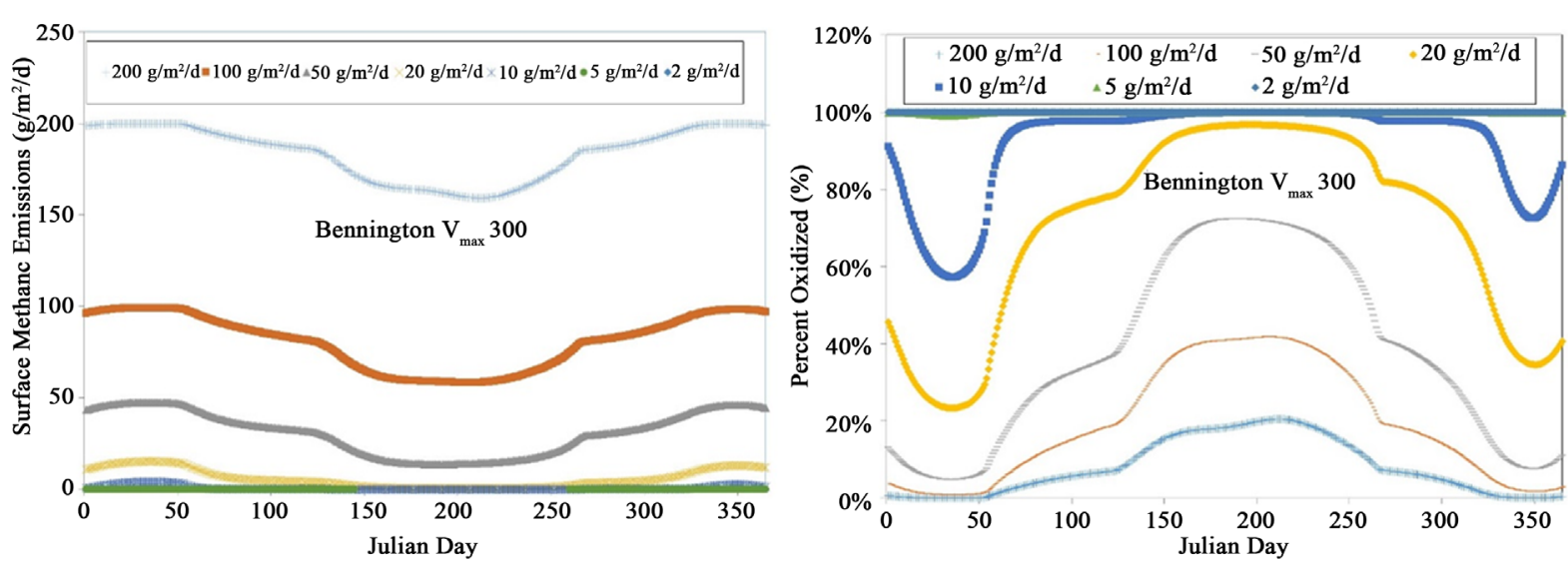

Figure 4. Surface emissions, percent oxidized for several methane loading fluxes with $V_{\max }=300 \mathrm{nmol} \cdot \mathrm{s}^{-1} \cdot \mathrm{g}^{-1} \mathrm{soil}$. 
during colder periods of the year. The higher percent oxidation and the lowest surface emissions occur during the growing season and during the spring and summer seasons indicating the effects of soil temperature and water contents on surface emissions and therefore methane oxidation.

The data presented in Figure 3 and Figure 4 were then used to calculate average yearly methane oxidation rate and average yearly percent oxidation for each simulated methane loading. The average yearly methane oxidation rate in $\mathrm{gm}^{-2} \mathrm{~d}^{-1}$ was determined for each MLF and plotted in Figure 5. Figure 5 shows that at lower MLFs, oxidation rate is equal to the MLF and increases with increasing MLF. In this region, the ET cover is able to oxidize all of the methane coming from below. In this region, the slope of the curve shown in Figure 5 is 1:1. In this region of low MLFs, there is no difference between the simulations with 150 and $300 \mathrm{nmol} \cdot \mathrm{s}^{-1} \cdot \mathrm{g}^{-1}$ dry soilsince both ET covers can oxidize all of the incoming methane. There seems to be an MLF below which methane oxidation is total (around $7-8 \mathrm{gm}^{-2} \cdot \mathrm{d}^{-1}$ for both $V_{\max }$ values). The methane loading flux at which the cover can oxidize all of the incoming methane can be considered as the MLF below which no surface emissions are measurable (No surface emissions). Above this MLF, the ET cover is not able to oxidize all of the incoming methane but still can oxidize more and more methane as the MLF increases. Figure 5 also shows that each ET cover soil seems to have a maximum capacity to oxidize the incoming methane depending on $V_{\max }$. Figure 5 shows that for each $V_{\max }$, there is a point where the ET cover will not oxidize any more methane, which indicates a certain capacity of the cover soil (around $13 \mathrm{gm}^{-2} \cdot \mathrm{d}^{-1}$ and $19 \mathrm{gm}^{-2} \cdot \mathrm{d}^{-1}$ for $V_{\max }$ of 150 and 300 respectively). Figure 5 also shows that oxidation rate starts to decrease after a certain MLF. We believe that this is due to the fact that these results are obtained using a pressure based model. The pressure below the landfill cover is increased to increase the MLF into the cover soil. At a certain pressure (depending on the cover) the incoming flux of methane starts to inhibit the diffusion of oxygen from the upper boundary and limit the amount of methane that can be oxidized.

The shape of the graph in Figure 5 resembles a Michaelis-Menten enzyme kinetic plot of a biological reactions response to increasing concentrations of a substrate. In landfill ET cover, soil methane oxidation is conducted by a biological system and it behaves as such. When substrate $\left(\mathrm{CH}_{4}\right)$ is supplied, the cover's rate of $\mathrm{CH}_{4}$ uptake is linear to a point, and then the system apparently becomes saturated. This response must be due to the oxygen levels to which the bacteria are exposed in addition to temporal variability in soil temperature and moisture.

The same simulation results were used to calculate the average percent year methane oxidation, and plotted versus MLF for each $V_{\max }$ in Figure 6. Figure 6 shows that there seems to be a methane loading rate below which methane oxidation is equal to $100 \%$. Above this methane loading, the cover is not able to oxidize all of the incoming methane. Therefore, percent oxidation starts to decrease as the methane loading increases. As expected, at any given MLF, ET covers with higher $V_{\max }$ have higher percent methane oxidation.

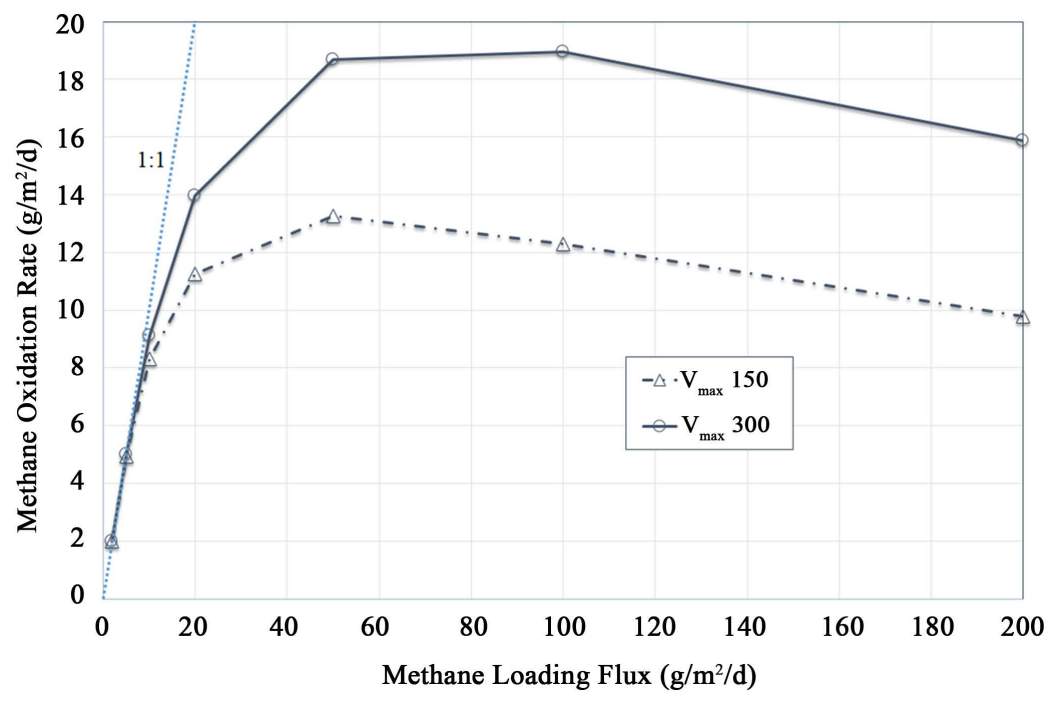

Figure 5. Methane oxidation rate versus MLF for simulations with $V_{\max }=150$ and $300 \mathrm{nmol} \cdot \mathrm{s}^{-1} \cdot \mathrm{g}^{-1}$ dry soil. 


\section{Conclusions and Practical Implications}

One way to estimate uncontrolled emissions or fugitive emissions from the surface of landfills is to use the AP42 protocol proposed by the United States Environmental Protection Agency (USEPA, 1997). AP-42, when applied to landfill methane surface emissions, can be written as follows:

$$
\mathrm{CM}_{\mathrm{P}}=\left[\mathrm{UM}_{\mathrm{P}} *\left(1-\frac{\eta_{c o l}}{100}\right)\right] *\left(1-f_{o x}\right)
$$

where $\mathrm{CM}_{\mathrm{P}}$ is the controlled mass emissions of methane ( $\left.\mathrm{kg} / \mathrm{year}\right), \mathrm{UM}_{\mathrm{P}}$ is the methane generation from the waste mass in $\mathrm{kg} /$ year (estimated by LANDGEM or any other allowed model), $\eta_{c o l}$ is the collection efficiency of the landfill gas collection system. The collection efficiency of the gas collection system can be assumed the default values of $75 \%$ assigned for soil covers. The remaining $25 \%$ of the generated methane can be assumed to escape through the landfill ET cover such as the one simulated in this study, $f_{o x}$ is the percent oxidation or fraction of methane oxidized in the cover soil. The USEPA has also allowed the use of $10 \%$ to account for methane oxidation that can occur in landfill cover soils.

One application of this model is to be used in conjunction of AP-42 guidelines but with a modeled methane oxidation, $f_{o x}$ instead of the default value of $10 \%$ typically assumed in AP-42. The use of the correlations of $f_{o x}$, shown in Figure 7, can encourage the use of ET covers and provide an estimate of fugitive methane emis-

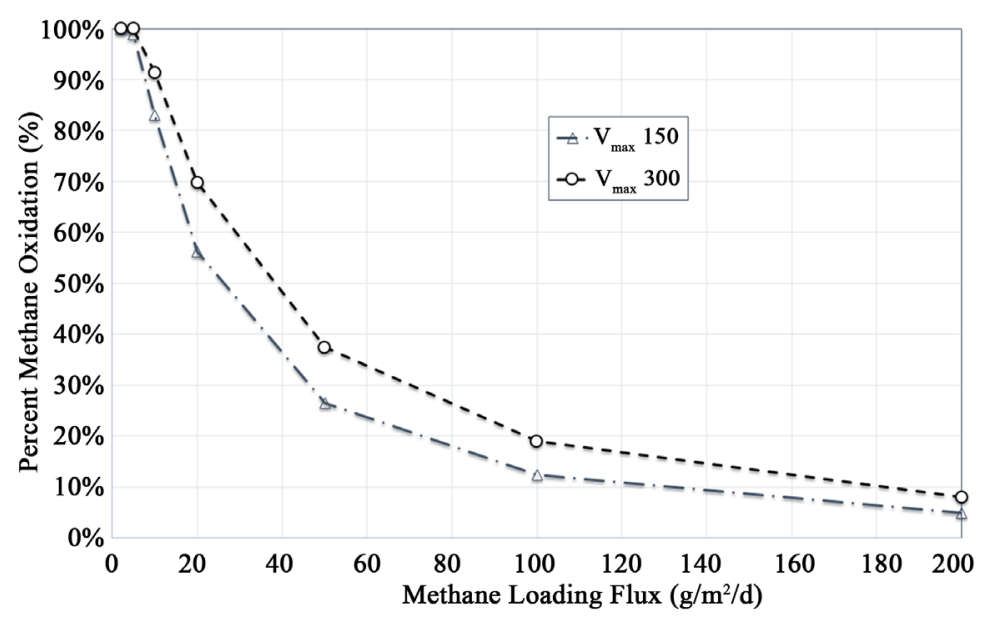

Figure 6. Percent methane oxidation versus MLF for simulations with $V_{\max }=150$ and 300 $\mathrm{nmol} \cdot \mathrm{s}^{-1} \cdot \mathrm{g}^{-1}$ dry soil.

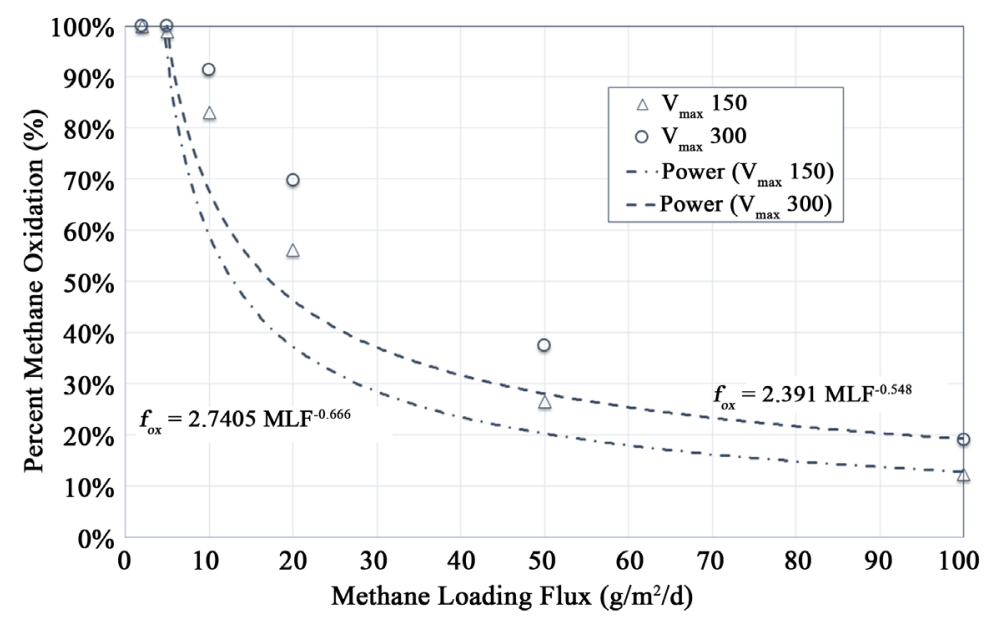

Figure 7. Correlation of Percent methane oxidation versus MLF for simulations with $V_{\max }=$ 150 and $300 \mathrm{nmol} \cdot \mathrm{s}^{-1} \cdot \mathrm{g}^{-1}$ dry soil. 
sions, along with quantifying the improvement of performance (emissions and oxidation) of ET covers. Such protocol can help decision makers quantify additional methane oxidation capabilities of ET covers. The modeled percent oxidation for each $V_{\max }$ was expressed as a power function of methane loading flux (MLF) as shown in Figure 7 . The methane loading flux is estimated as the $25 \%$ of generation (methane escaping the gas collection system) divided by the surface area of the ET covered landfill.

\section{References}

[1] Albrecht, B. and Benson, C. (2001) Effect of Desiccation on Compacted Natural Clays. J. of Geotech. and Geoenv. Eng., ASCE, 127, 67-76.

[2] Benson, C. and Khire, M. (1995) Earthen Covers for Semi-Arid and Arid Climates, ASCE 1995 National Convention on Landfill Closures-Environmental Protection and Land Recovery. Geotechnical Special Publication No. 53, 201-217.

[3] Stormont, J. and Morris, C. (1998) Method to Estimate Water Storage Capacity of Capillary Barriers. Journal of Geotechnical and Geoenvironmental Engineering, 124, 297-302. http://dx.doi.org/10.1061/(asce)1090-0241(1998)124:4(297)

[4] Nyhan, J.W., Schofield, T.G. and Starmer, R.H. (1997) A Water Balance Study of Four Landfill Cover Designs Varying in Slope for Semi-Arid Regions. Journal of Environmental Quality, 26, 1385-1392. http://dx.doi.org/10.2134/jeq1997.00472425002600050026x

[5] Ward, A.L. and Gee, G. (1997) Performance Evaluation of a Field-Scale Surface Barrier. Journal of Environmental Quality, 26, 694-705. http://dx.doi.org/10.2134/jeq1997.00472425002600030015x

[6] Hauser, V., Weand, B., Shaw, M. and Wusterbarth, A. (1996) Natural Covers for Landfills: A Closer Look. Proceedings of the 22nd Symposium and Exhibition, American Defense Preparedness Association, Orlando, March 1996.

[7] Bogner, J., Spokas, K., Burton, E., Sweeney, R. and Corona, V. (1995) Landfills as Atmospheric Methane Sources and Sinks. Chemosphere, 31, 4119-4130. http://dx.doi.org/10.1016/0045-6535(95)80012-A

[8] Borjesson, G. and Svensson, B. (1997) Seasonal and Diurnal Methane Emissions from a Landfill and Their Regulation by Methane Oxidation. Waste Management and Research, 15, 33-54.

[9] Abichou, T., Chanton, J., Powelson, D., Fleiger, J., Escoriaza, S., Lei, Y. and Stern, J. (2006) Methane Flux and Oxidation at Two Types of Intermediate Landfill Covers. Waste Management, 26, 1305-1312. http://dx.doi.org/10.1016/j.wasman.2005.11.016

[10] Kjeldsen, P., Dalager, A. and Broholm, K. (1997) Attenuation of Methane and Nonmethane Organic Compounds in Landfill Gas Affected Soils. Journal of Air \& Waste Management Association, 47, 1268-1275. http://dx.doi.org/10.1080/10473289.1997.10464072

[11] Scheutz, K., Kjeldsen, P., Chanton, J., Blake, D. and Bogner, J. (2003) Comparative Oxidation and Net Emissions of CH4 and Selected Non-CH4 Organic Compounds in Landfill Cover Soils. Environmental Science and Technology, 37, 5150-5158. http://dx.doi.org/10.1021/es034016b

[12] Huber-Humer, M., Gebert, J. and Hilger, H. (2008) Biotic Systems to Mitigate Landfill Methane Emissions. Water Management Research, 26, 33-46. http://dx.doi.org/10.1177/0734242x07087977

[13] Bogner, J. and Spokas, K. (1993) Landfill CH4: Rates, Fates, and Role in Global Carbon Cycle. Chemosphere, 26, 369-386. http://dx.doi.org/10.1016/0045-6535(93)90432-5

[14] Abichou, T., Mahieu, K., Chanton, J., Romdhane, M. and Mansouri, I. (2011) Scaling Methane Oxidation: From Laboratory Incubation Experiments to Landfill Cover Field Conditions. Waste Management, 31, 978-986. http://dx.doi.org/10.1016/j.wasman.2010.12.002

[15] Abichou, T., Mahieu, K., Yuan, L., Chanton, J. and Hater, G. (2009) Effects of Compost Biocovers on Gas Flow and Methane Oxidation in a Landfill Cover. Waste Management, 29, 1595-1601. http://dx.doi.org/10.1016/j.wasman.2008.11.007

[16] Yuan, L., Abichou, T., Chanton, J., Powelson, D. and De Visscher, A. (2009) Long Term Numerical Solution of Methane Transport and Oxidation in a Compost Biofilter. Practice Periodical of Hazardous Toxic and Radioactive Waste Management, 13, 196-202. http://dx.doi.org/10.1061/(ASCE)1090-025X(2009)13:3(196)

[17] Abichou, T., Yuan, L. and Chanton, J. (2008) Estimating Methane Emission and Oxidation from Earthen Landfill Covers. Geocongress 2008: Geotechnics of Waste Management and Remediation (GSP), New Orleans, 9-12 March 2008, 80-87. http://dx.doi.org/10.1061/40970(309)10

[18] Abichou, T., Johnson, T., Mathieu, K., Chanton, J., Romdhane, M. and Mansouri, I. (2010) Developing a Design Approach to Reduce Methane Emissions from California Landfills. In: Fratta, D., Muhuntan, B. and Pupala, A., Eds., GeoFlorida 2010: Advances in Analysis, Modeling \& Design, ASCE, Geotechnical Special Publication No. 199, Baltimore, 2878-2887. 
[19] Spokas, K. and Forcella, F. (2009) Software Tools for Weed Seed Germination Modeling. Weed Science, 57, $216-227$. http://dx.doi.org/10.1614/WS-08-142.1

[20] Jin, Y. and Jury, A. (1996) Characterizing the Dependence of Gas Diffusion Coefficient on Soil Properties. Soil Science Society of America Journal, 60, 66-71. http://dx.doi.org/10.2136/sssaj1996.03615995006000010012x

[21] Stein, V. B., Hettiaratchi, J. and Achari, G. (2003) Numerical Model for Biological Oxidation and Migration of Methane in Soils. Practice Periodical of Hazardous, Toxic, and Radioactive Waste Management, 5, 225-234. http://dx.doi.org/10.1061/(ASCE)1090-025X(2001)5:4(225)

[22] Freijer, J. (1994) Calibration of Jointed Tube Model for the Gas Diffusion Coefficient in Soils. Journal of the American Society of Soil Science, 58, 1067-1076. http://dx.doi.org/10.2136/sssaj1994.03615995005800040010x

[23] Kightley, D., Nedwell, D. and Cooper, M. (1995) Capacity for Methane Oxidation in Landfill Cover Soils Measured in Laboratory Scale Soil Microcosms. Journal of Applied Environmental Microbiology, 61, 592-601.

[24] Moldrup, P., Olesen, T., Gamst, J., Schjønning, P., Yamaguchi, T. and Rolston, D.E. (2000) Predicting the Gas Diffusion Coefficient Inrepacked Soil: Water-Induced Linear Reduction Model. Soil Science Society of America Journal, 64, 1588-1594. http://dx.doi.org/10.2136/sssaj2000.6451588x 